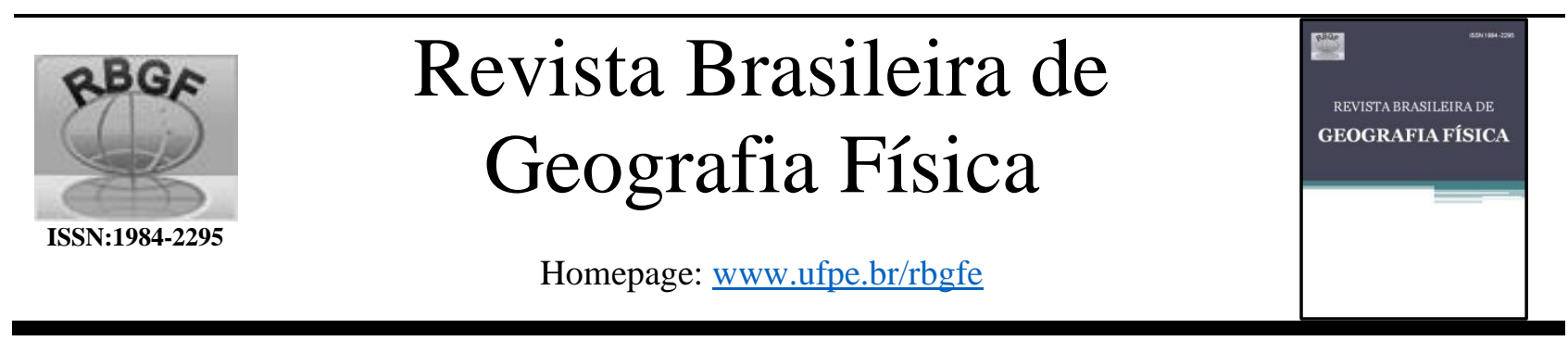

\title{
Avaliação do Potencial de Aproveitamento de Aluviões para a Construção de Barragens Subterrâneas no Semiárido Pernambucano
}

\author{
Eronildo Luiz da Silva Filho', Tiago Oliveira Caetano², Thaise Suanne Guimarães Ferreira ${ }^{1}$, José Almir \\ Cirilo $^{3}$, Rochele Sheila Vasconcelos ${ }^{4}$, Tatiane Barbosa Veras de Albuquerque ${ }^{5}$
}

\begin{abstract}
${ }^{1}$ Mestrandos em Engenharia Civil e Ambiental, Centro Acadêmico do Agreste, Universidade Federal de Pernambuco (UFPE), Caruaru-PE. eronildo.luiz.silva@gmail.com, thaisesuanne14@gmail.com . ${ }^{2}$ Doutorando em Engenharia Civil, Centro de Tecnologia e Geociências, Universidade Federal de Pernambuco (UFPE), Recife-PE. tiagooliveiracaetano@ gmail.com. ${ }^{3}$ Professor Titular do Centro Acadêmico do Agreste, Universidade Federal de Pernambuco (UFPE), Caruaru-PE. almir.cirilo@gmail.com. ${ }^{4}$ Pós-doutoranda do Centro Acadêmico do Agreste, Universidade Federal de Pernambuco (UFPE), Caruaru-PE. rochelly17@ hotmail.com (autora correspondente). ${ }^{5}$ Doutora em Engenharia Civil, Centro de Tecnologia e Geociências, Universidade Federal de Pernambuco (UFPE), Recife-PE. tatianeveras @ yahoo.com.br.
\end{abstract}

Artigo recebido em 03/01/2020 e aceito em 14/05/2020

\section{R E S U M O}

Diante da histórica escassez de recursos hídricos na região semiárida, é notória a necessidade de se encontrar novas fontes de obtenção e armazenamento de água, seja para o consumo humano e animal ou para produção agrícola. A implantação de barragens subterrâneas no semiárido brasileiro pode contribuir de forma positiva na melhoria do abastecimento humano em comunidades rurais, além do fornecimento de água para o consumo animal e para produção de alimentos. Como sua construção se dá em os solos aluviais, o presente estudo tem como objetivo avaliar o potencial de aproveitamento desses solos no estado de Pernambuco para a implantação de barragens subterrâneas e verificar as áreas passíveis de salinização para a escolha adequada desse tipo de intervenção. A área de estudo corresponde ao estado de Pernambuco, em que a presença de solos aluviais foi observada por bacia hidrográfica, utilizando os dados do Zoneamento Agroecológico do Estado de Pernambuco (ZAPE). Com a mesma base de dados foram selecionados os solos com características salinas e estimada, por aluvião, a capacidade de armazenamento de água. Foi possível verificar que o estado de Pernambuco apresenta consideráveis áreas de solos aluviais, com potencial para aproveitamento das águas subterrâneas através da construção de barragens subterrâneas, bem como identificar as regiões onde a implantação desse tipo de obra deve estar aliada a um plano de manejo por conta do risco de salinização. Palavras-chave: água subterrânea, aluvião, barragens subterrâneas, risco de salinização.

\section{Evaluation of the Alluvial Use Potential for a Construction of Underground Dams in the Semi-Arid Region of Pernambuco}

\section{A B S T R A C T}

Given the historical scarcity of water resources in the semi-arid region, it is clear the need to find new sources for obtaining and storing water, either for human and animal consumption or for agricultural production. The establishment of underground dams in the Brazilian semi-arid region can contribute positively to the improvement of human supply in rural communities, as well as the supply of water for animal consumption and food production. As its construction takes place on alluvial soils, the present study aims to evaluate the potential use of alluvial soils in the state of Pernambuco for the implantation of underground dams and to verify the salinization areas for the appropriate choice of this type of intervention. The study area corresponds to the state of Pernambuco, where the presence of alluvial soils was observed by watershed, using data from Pernambuco State Agroecological Zoning (ZAPE). With the same database were selected soils with saline characteristics and estimated, in each alluvium, water storage capacity. It was possible to verify that the state of Pernambuco has areas considerable of alluvial soils, with potential for groundwater utilization and for the construction of underground dams, as well as to identify the regions where the implementation of this type of work should be more restrictive due to the risk of salinization.

Keywords: groundwater, alluvium, subsurface dam, risk of salinization.

\section{Introdução}

Silva Filho, E. L.; Caetano, T. O.; Ferreira, T. S. G.; Cirilo, J. A., Vasconcelos, R. S.; Albuquerque, T. B. V. 
Os recursos hídricos são fundamentais para o desenvolvimento econômico de uma região, tendo em vista que a água é um bem essencial para o consumo humano e para o desenvolvimento econômico, seja este agrícola ou industrial.

Mais de $70 \%$ da população mundial enfrenta escassez pelo menos moderada de água em no mínimo um mês por ano (Mekonnen e Hoekstra, 2016). Na região semiárida do Nordeste brasileiro a precipitação apresenta alta variabilidade espacial e temporal e nos últimos tempos extremos climáticos (secas e cheias) são ainda mais frequentes (Cabral et al., 2016), ocasionando problemas para a população quanto ao acesso a água (Adham et al., 2016; Silva et al., 2017). A baixa disponibilidade hídrica traz graves consequências socioeconômicas para a população (Eakin et al., 2014). A escassez desse recurso, não se limita apenas em quantidade, como em qualidade também, dificultando ainda mais as condições de vida da população que reside nesta região.

No entanto, medidas para contornar os impactos causados pela seca foram aplicadas. Pode-se citar, por exemplo, o Programa de Formação e Mobilização Social para Convivência com o Semiárido: Um Milhão de Cisternas Rurais (P1MC), executado pela ASA (Articulação no Semiárido Brasileiro) e tendo como principal financiador o Governo Federal através do Ministério de Desenvolvimento Social e Combate à Fome-MDS, sendo esta, uma das medidas de maior relevância para a convivência com a seca (Gomes e Heller, 2016). Outras ações importantes são a perfuração de poços, construção de barragens e instalação de dessalinizadores.

A implementação de barragens subterrâneas (BS) no semiárido pode contribuir de forma positiva na melhoria do abastecimento humano em comunidades rurais, além do fornecimento de água para o consumo animal e para produção de alimentos, pois apresentam grande potencial de armazenamento de água subterrânea (Alves et al., 2018; Lima et al., 2018; Jamali et al., 2018).

As barragens subterrâneas são construídas para interromper o fluxo subsuperficial natural dos rios sazonais e armazenar a água no subsolo (Lalehzari e Tabatabaei, 2015; Stevanović, 2016; Alves et al., 2018; Sheikhipour et al., 2018). Com a implantação da BS a produção de alimentos tem seu potencial elevado através do uso da irrigação. Os agricultores podem usar a água armazenada durante a estação seca, minimizando os riscos iminentes da agricultura de sequeiro, fortalecendo as comunidades rurais.
A escolha por barragem subterrânea, frente ao represamento superficial torna-se mais interessante em regiões semiáridas devido a diminuição da evaporação pelo armazenamento da água no macroporos do solo (Ouerdachi et al., 2012), já que a evapotranspiração potencial no semiárido pode atingir valores superiores a 2.000 $\mathrm{mm} / \mathrm{ano}$ (Lafayette et al., 2019). As barragens subterrâneas têm um grande potencial a ser aproveitado, pois o seu baixo custo, baixa necessidade de área para alagamento e facilidade de construção, potencializam o retorno de benefícios (Cirilo et al., 2003). Apesar das vantagens apresentadas, algumas deficiências são observadas, como dificuldade na seleção do local em potencial para sua construção, baixa efetividade do armazenamento de água e salinização da área do reservatório.

Segundo Fontes Júnior et al. (2012), na maioria das vezes, os fatores que restringem o uso e a disponibilidade das águas subterrâneas estão diretamente ligados à sazonalidade e à variabilidade espacial dos níveis de acumulação e a salinidade. Fatores como balanço hídrico deficitário, onde a evapotranspiração é maior do que a precipitação, drenagem deficiente e os componentes dos solos transportados afetam o acúmulo de sais (Freire et al., 2014).

A salinidade do solo é um fator limitante para a produção agrícola (Li et al., 2018). Como parte do objetivo de aumentar a disponibilidade hídrica através das barragens subterrâneas é para a para produção agrícola, as características do solo onde serão implantadas tem grande relevância, pois a prática de irrigação com manejo inadequado já é um grande problema causador da salinização do solo, a mesma associada a solos com propriedades salinas tem seu efeito multiplicador, fato observado por Soares et al. (2016), no qual solos propícios a salinização quando mantido sua vegetação natural não apresentaram o mesmo problema.

O conhecimento prévio do tipo de solo constituinte de cada região é de grande valia para a agricultura, possibilitando conhecimento prévio de quais culturas se adaptam ao tipo de solo, para o planejamento de recursos hídricos na definição de barramentos, projetos de irrigação, risco de salinização, entre muitas outras ações que dependem das características dos solos.

Avaliar os graus de salinização, os riscos e os fatores principais que contribui para o excesso de sais nos solos das áreas susceptíveis à desertificação torna-se importante, visto que, é um fator fundamental para o planejamento e a fomentação de ações e políticas públicas voltadas para os manejos adequados de cada ambiente. 
O uso do SIG desempenha um papel crucial para o mapeamento da potencialidade da água subterrânea, oferecendo a capacidade de armazenar, manipular e analisar dados em diferentes formatos e em diferentes escalas. Com relevância na obtenção de informações para áreas onde os dados do solo não estão prontamente disponíveis (Chezgi et al., 2016; Santos e Mariano, 2017; Kharazi et al., 2019). A integração de diversas variáveis em estudo pode permitir uma demarcação rápida e relevante das zonas potenciais das águas subterrâneas (Agarwal e Garg, 2016).

Para implementação de barragens subterrâneas, o primeiro passo é identificar os locais adequados para a construção, uma vez que essas barragens só são viáveis em algumas áreas, dependendo do tipo de solo e geologia do local. O desenvolvimento da barragem subterrânea é acompanhado por riscos técnicos devido à falta de informações precisas que deveriam estar disponíveis antes do início da construção (Lalehzari e Tabatabaei, 2015; Dortaj et al., 2020).

A hipótese é que há expressivas ocorrências de aluviões em regiões onde há escassez hídrica e que a utilização de dados espaciais na identificação dos solos que mais contribuem para a salinização dos aquíferos pode gerar um conjunto de informações que podem contribuir significativamente para o planejamento de alocação de barragens subterrâneas no estado de Pernambuco.

Em consonância com as questões citadas, este estudo tem como objetivo avaliar o potencial de aproveitamento dos solos aluviais do estado de Pernambuco para a implantação de barragens subterrâneas, a partir da estimativa dos recursos explotáveis e dos possíveis riscos de salinização em diferentes formações aluviais.

\section{Material e métodos}

O estado de Pernambuco se divide em 29 Unidades de Planejamento hídrico (UP), representadas na Figura 1. São 13 Bacias Hidrográficas, 6 Grupos de Bacias de Pequenos Rios Litorâneos (GL1 a GL6), 9 Grupos de Bacias de Pequenos Rios Interiores (GI1 a GI9) e uma bacia de pequenos rios que compõem a rede de drenagem do arquipélago de Fernando de Noronha (ANA, 2019).

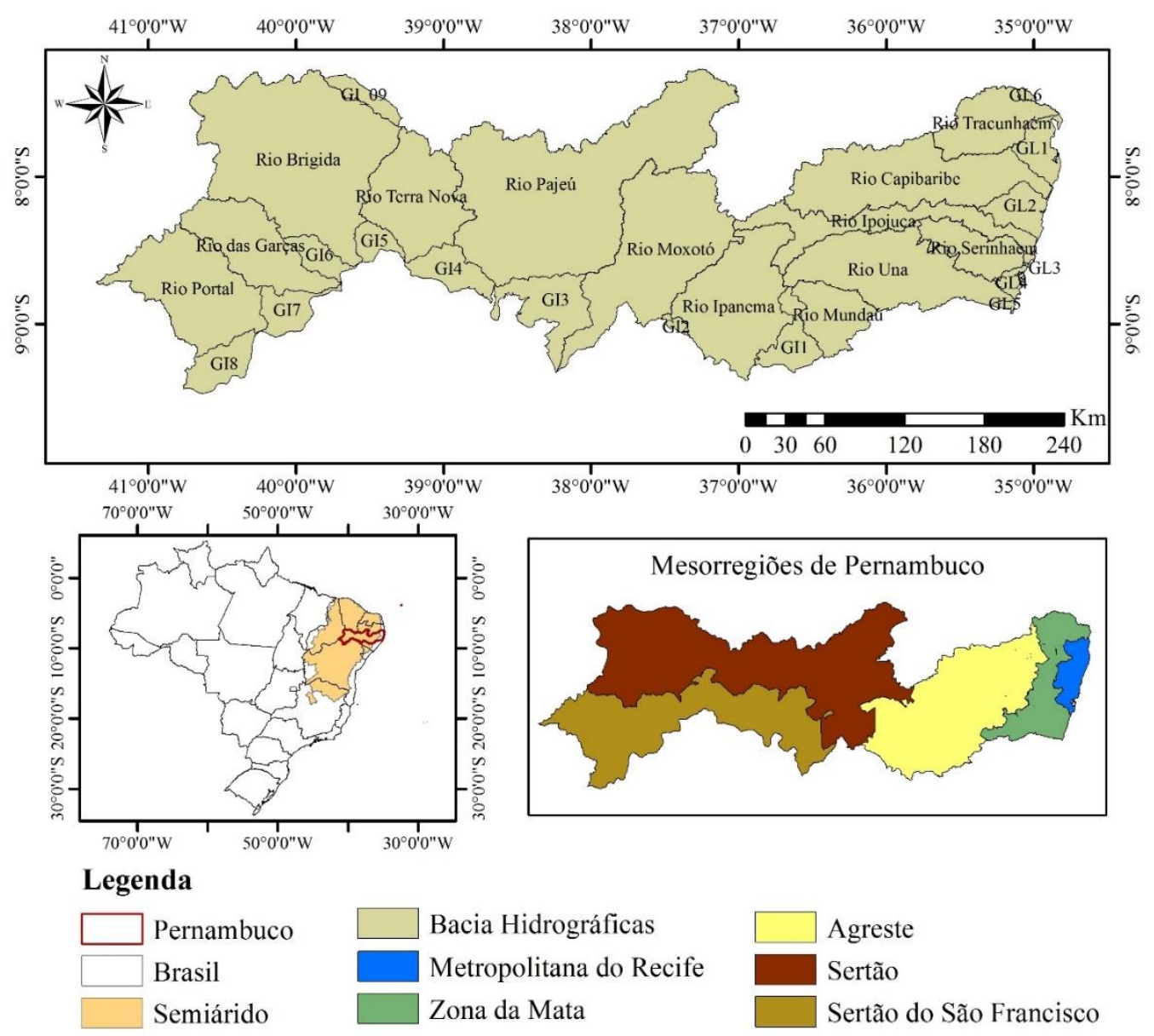

Figura 1. Mapa de localização do estado de Pernambuco e sua divisão por Unidade de Planejamento - (UP).

Silva Filho, E. L.; Caetano, T. O.; Ferreira, T. S. G.; Cirilo, J. A., Vasconcelos, R. S.; Albuquerque, T. B. V. 
O Estado apresenta grande variabilidade climática em função da sua localização geográfica. As maiores precipitações ocorrem no litoral do Estado, apresentando totais anuais médios entre 1000 e $2300 \mathrm{~mm}$. No Agreste esse valor é inferior a $800 \mathrm{~mm}$ e no Sertão oscila entre 400 e $600 \mathrm{~mm}$ (PERNAMBUCO, 2006).

A fim de demarcar zonas de prospecção de água subterrânea e avaliar os riscos de salinização, diferentes mapas temáticos foram elaborados a partir de dados remotamente detectados e dados convencionais.

O software livre QGis foi usado para delimitar as bacias hidrográficas e se obter as declividades do terreno, com isso gerando-se a rede de cursos d'água. Para isso foi utilizada a base de dados espaciais do Shuttle Radar Topography Mission (SRTM), com resolução de 30 metros. O estado de Pernambuco dispõe de dados espaciais de alta resolução (Cirilo et al., 2014) gerada com a tecnologia LiDAR (Light Detection and Ranging), porém o processamento desses dados para a cobertura de todo o estado é inviável do ponto de vista computacional.

Após a obtenção dos cursos d'água foi possível sobrepor os solos aluviais obtidos da base de dados do Zoneamento Agroecológico - ZAPE (EMBRAPA, 2001). O Zoneamento Agroecológico do Estado de Pernambuco - ZAPE foi empreendido pela Secretaria de Produção Rural e Reforma Agrária de Pernambuco em convênio com a Embrapa. Neste estudo foram levantados os tipos de solos constituintes do estado na escala 1:100.000. As formações aluviais foram separadas dos demais tipos de solos, em seguida foram corrigidas falhas de continuidade nos shapefiles, para quantificação de extensões, áreas e posteriormente a capacidade de armazenamento de água nestas formações.

Como um dos objetivos é classificar as aluviões quanto ao possível volume armazenável, fez-se necessário estimar a profundidade destes solos. Na literatura encontram-se informações sobre a profundidade de algumas aluviões ao longo do Estado. Para uma região do Capibaribe foi encontrada uma variação média em torno de 3 metros e meio (Caetano, 2018). Nessa mesma região no trecho do Alto rio Capibaribe 119 poços rasos foram cadastrados, sendo que 55\% destes apresentam profundidades de 3,00 a 5,00 metros (Paiva, 2014). Para a região da bacia do Pajeú, na cidade de Afogados da Ingazeira, as aluviões estudadas apresentaram profundidade de 2,80 metros (Rodrigues, 2012). Nessa mesma bacia foram identificadas por Silva (1994), aluviões com média de profundidade de 4,50 metros. Utilizou-se assim para a avaliação geral uma espessura da camada aluvial de 3 metros. Ressalta-se que essa pode ser uma estimativa conservadora, visto que a profundidade dos solos, principalmente no sertão, pode ser superior, de acordo com a literatura citada.

O cálculo do volume se deu pela multiplicação da área, da profundidade e da porosidade efetiva da aluvião. A porosidade efetiva adotada foi de $25 \%$, um valor intermediário entre os valores determinados em estudos realizados em aluviões do Agreste e do Sertão pernambucanos (Rodrigues, 2012; Caetano, 2018).

Outro aspecto avaliado diz respeito ao risco de salinização. Com o cruzamento dos dados obtidos - manchas de solos aluviais selecionadas, identificação dos solos com tendência à liberação de sais e traçado dos cursos d'água - foi possível caracterizar cada aluvião quanto à tendência à salinização.

Diante disso, ainda com os dados do ZAPE, foram selecionados apenas os shapefiles contendo os solos com características propícias a salinização, sendo eles: Cambissolos Háplicos, Luvissolos Crômicos, Neossolos Quartzarênicos, Planossolos Háplicos e Vertissolos Háplicos.

Na classificação levou-se em consideração uma faixa do tipo de solo mais passível à salinização ao com menor risco. A metodologia utilizada foi a classificação SiBCS - Sistema Brasileiro de Classificação de Solos, desenvolvido pela EMBRAPA (2006). Essa classificação se dá em 6 níveis, sendo os quatro primeiros designados de ordem, sub-ordem, grupos e subgrupos. O nível 5 encontra-se em discussão e o $6^{\circ}$ não foi definido para o país.

Para o presente estudo foi observado em qual nível se encontram as propriedades salinas nos tipos de solos estudados (Figura 2). Segundo AGEITEC (2014a), os Cambissolos Háplicos possuem 12 classificações no terceiro nível. Entre elas tem-se a classificação como sódico, em níveis de toxidade em culturas, e dessa forma tem-se o Cambissolo Háplico sódico, em terceiro nível.

O Luvissolo Crômico não possui no terceiro nível característica salina. Partindo para o quarto nível encontram-se dois sub-grupos com propriedades salinas, os Salinos e Solódicos, e assim as categorias Luvissolo Crômico Órtico Salino e Luvissolo Crômico Órtico Solódico, Figura 2 (AGEITEC, 2014b).

O Neossolo Quartzarênico possui 2 grupos no terceiro nível, nenhum diretamente classificado como salino. No quarto nível, dentro do grupo dos órticos, encontra-se o subgrupo solódico. Como 
resultado tem-se o Neossolo Quartzarênico Órtico Solódico, com propriedades salinas (AGEITEC, 2014c).

O Planossolo Háplico possui 4 grupos no terceiro nível, entre eles o sálico, em quantidades tóxicas às plantas, e ainda o subgrupo solódico. Descendo para o nível dos subgrupos encontram-se mais 4 com propriedades salinas (AGEITEC, 2014d).

Já no caso do Vertissolo Háplico, segundo AGEITEC (2014e), os 2 grupos do terceiro nível se caracterizam pela ocorrência de sais, sendo eles o sódico e o sálico.

Figura 2. Classificação dos solos em níveis (Propriedades salinas e sódicas em vermelho)

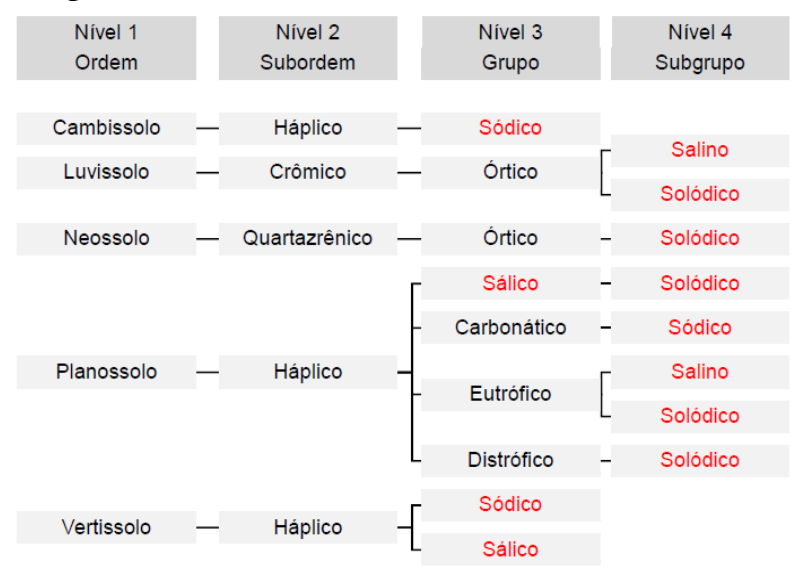

Fonte: autor, 2019.

Diante do disposto, os solos foram ordenados quanto a capacidade de salinização e foi avaliada possibilidade de sofrer salinização nos barramentos que vierem a ser executados, de acordo com o nível onde as características salinas ou sódicas estão e em que frequência em cada tipo de solo.

\section{Resultados e discussão}

Como resultado foi obtido um mapa com os solos aluviais por bacia hidrográfica ou grupos de bacias do território pernambucano (Figura 3). A área total de solos aluviais foi avaliada em cerca de 197 mil hectares, distribuída em todas as mesorregiões do estado. A capacidade de armazenamento de água nas aluviões foi calculada em 1.408 hectômetros cúbicos $(1,408$ bilhões de $\mathrm{m}^{3}$ ). Da área total compreendida pelas reservas, $96,15 \%$ se encontra em região semiárida, cortada pelos leitos secos dos seus cursos d'água intermitentes.

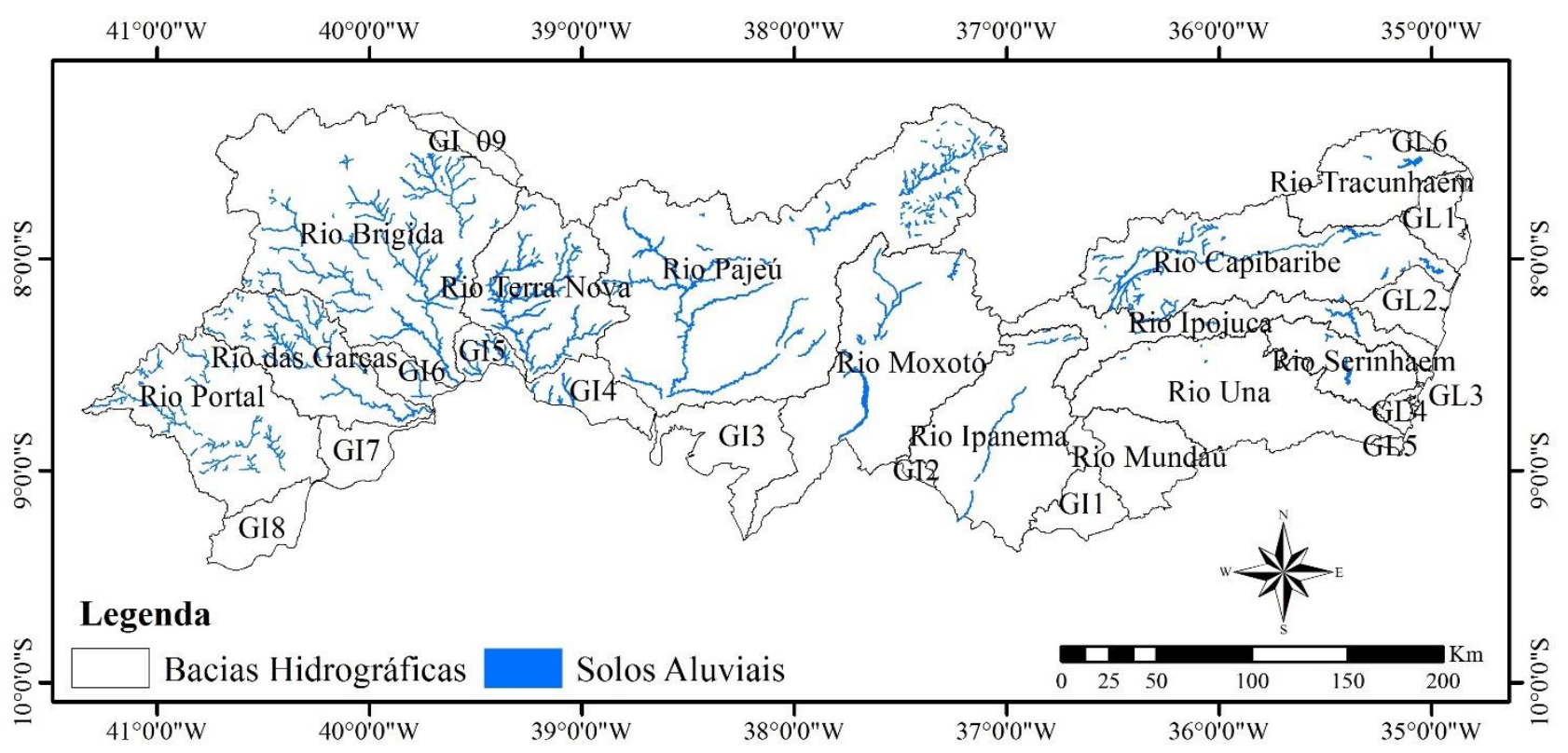

Figura 3. Distribuição espacial dos solos aluviais por Unidade de Planejamento em Pernambuco.

Na Tabela 1 registra-se a área da aluvião em hectares e sua capacidade de armazenamento de água estimada em metros cúbicos por bacia hidrográfica. As bacias do rio Pajeú e do rio Brígida, no Sertão do estado, são as que possuem as maiores áreas de aluviões, com 44.837 e 38.507 hectares, respectivamente. Em seguida destacamse as bacias do rio Terra Nova, também no Sertão, e do rio Capibaribe, no Agreste.

Silva Filho, E. L.; Caetano, T. O.; Ferreira, T. S. G.; Cirilo, J. A., Vasconcelos, R. S.; Albuquerque, T. B. V. 
Na Figura 4 são destacadas as 15 maiores aluviões selecionados para o estudo do risco de salinização. Sua descrição quanto a área em hectares, código de identificação (ID) aqui usado, municípios abrangidos e a capacidade de acumulação em metros cúbicos encontram-se indicados na Tabela 2.

As 15 maiores aluviões estão localizadas em 6 bacias hidrográficas: Capibaribe, Moxotó, Pajeú, Terra Nova, Brígida e Garças.

Tabela 1. Área da aluvião e a estimativa do potencial de volume armazenável por Unidade de Planejamento.

\begin{tabular}{ccc}
\hline $\begin{array}{c}\text { Unidade de } \\
\text { Planejamento }\end{array}$ & Área (ha) & Volume $\left(\mathbf{m}^{\mathbf{3}}\right)$ \\
\hline Pajeú & 44837 & $3.36 \mathrm{E}+08$ \\
Brígida & 38507 & $2.89 \mathrm{E}+08$
\end{tabular}

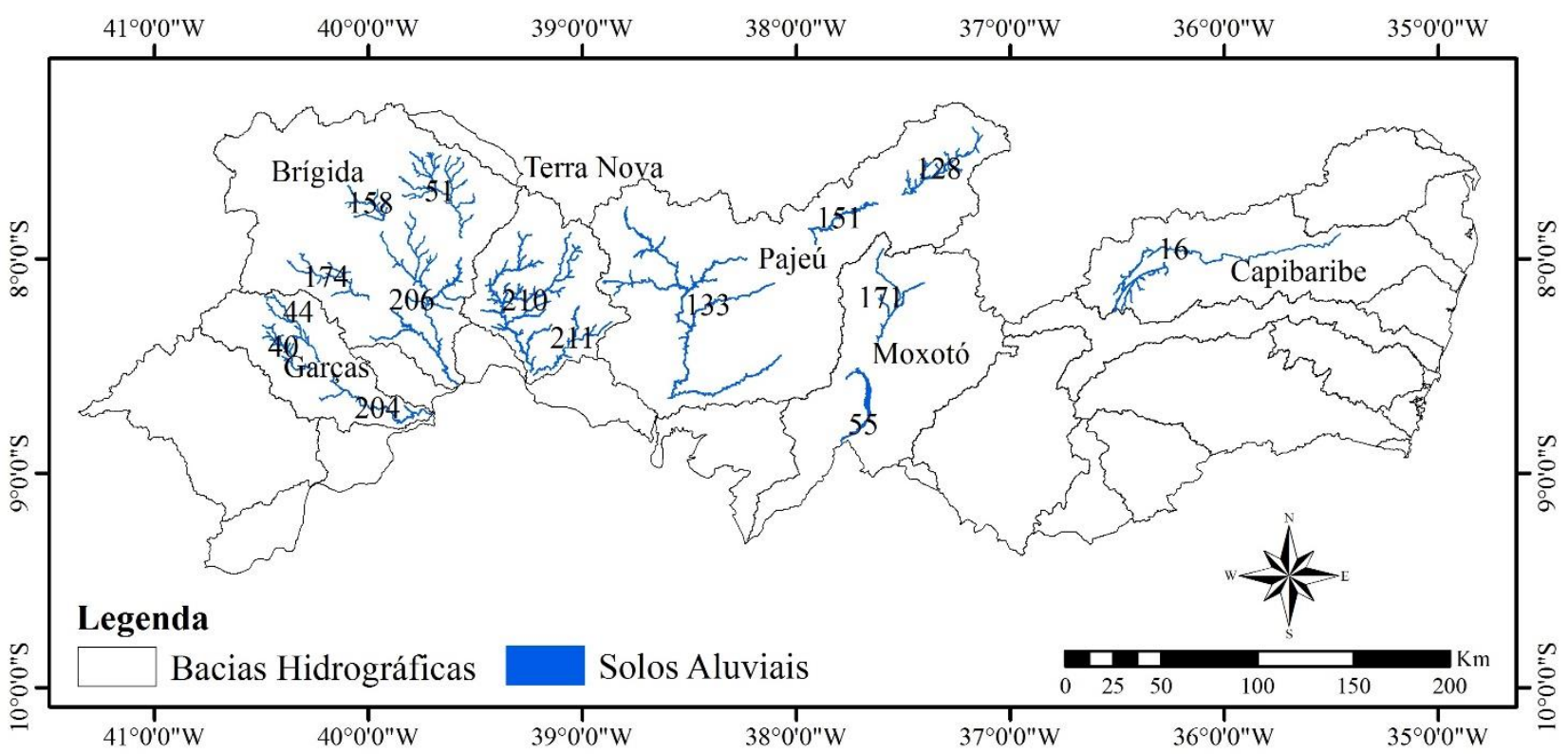

Figura 4. Maiores reservas de solos aluviais identificadas no estado de Pernambuco.

A maior aluvião (ID 133) está localizada na porção sudoeste da bacia do rio Pajeú, estendendo-se de montante para jusante, do município de São José do Belmonte, localizado próxima à divisa com o estado do Ceará, até o município de Floresta. Na bacia do rio Pajeú ainda estão presentes, na porção mais a nordeste da bacia, as aluviões ID 128 e ID 151 , respectivamente a $7^{\text {a }}$ e a $12^{\mathrm{a}}$ maiores aluviões do estado.

Na bacia do rio Terra Nova estão a $2^{\text {a }}$ (ID 210) e a $9^{\text {a }}$ (ID 211) maiores aluviões identificadas. A aluvião ID 210 tem ampla extensão, englobando a calha principal do rio Terra Nova, desde local próximo às nascentes na divisa com o Ceará até o seu deságue na margem esquerda do rio São
Francisco, e também o rio Salgueiro, maior afluente do Terra Nova, que drena as cidades de Salgueiro e Verdejante.

Das 15 maiores aluviões 4 estão localizadas na bacia do rio Brígida (ID 206, ID 51, ID 174 e ID 158). A ID 51, $5^{a}$ maior do estado, está localizada em área próxima das nascentes do rio Brígida, se estendendo desde o norte do município de Exu até o norte do município de Parnamirim, região próxima à divisa entre os municípios de Granito e Serrita. A aluvião $206,3^{\mathrm{a}}$ maior do estado, corresponde ao baixo e o médio curso do rio Brígida e as aluviões 158 e $174\left(11^{\mathrm{a}}\right.$ e $15^{\mathrm{a}}$ maiores, respectivamente) a riachos mais a oeste da bacia. 
Já a aluvião ID16, do rio Capibaribe, abrange o maior número de municípios em sua extensão, dentre as estudadas, totalizando 16 municípios. Com capacidade de armazenamento de água avaliada em 68,4 hectômetros cúbicos, compreende todo o alto e médio curso do rio, trechos onde este é intermitente.

A $6^{\mathrm{a}}$ e a $10^{\mathrm{a}}$ maiores aluviões (ID 55 e ID 171, respectivamente) estão localizadas no trecho pernambucano da bacia do rio Moxotó. De montante para jusante (direção norte/sul), a ID 171, mais próxima às nascentes, está situada majoritariamente nos municípios de Custória e Sertânia e a ID 55 localiza-se mais ao sul da bacia, partindo de Ibimirim em direção ao estado de Alagoas.

Na bacia do rio das Garças, que possui as nascentes no oeste do estado de Pernambuco, próximo à divisa com o Piauí, estão localizadas a $8^{\mathrm{a}}, 13^{\mathrm{a}}$ e $14^{\mathrm{a}}$ maiores aluviões (ID 201, ID 40 e ID 44 , respectivamente).

Tabela 2. Características dos solos aluviais selecionados

\begin{tabular}{|c|c|c|c|c|}
\hline Bacia & ID da aluvião & Área (ha) & Municípios abrangentes & $\begin{array}{c}\text { Capacidade } \\
\text { de } \\
\text { acumulação } \\
\text { de água }\left(\mathrm{hm}^{3}\right)\end{array}$ \\
\hline \multirow{3}{*}{ Pajeú } & 133 & 23315 & $\begin{array}{c}\text { São José do Belmonte, Serra Talhada, Mirandiba, } \\
\text { Floresta }\end{array}$ & 174,9 \\
\hline & 128 & 5811 & $\begin{array}{c}\text { Itapetim, São José do Egito, Tabira, Tuparetama, } \\
\text { Ingazera }\end{array}$ & 43,6 \\
\hline & 151 & 3639 & Afogados da Ingazeira, Carnaúba, Flores & 27,3 \\
\hline \multirow{2}{*}{ Terra Nova } & 210 & 22208 & $\begin{array}{c}\text { Verdejante, Serrita, Salgueiro, Terra Nova, } \\
\text { Cabrobó, Parnamirim }\end{array}$ & 166,6 \\
\hline & 211 & 4450 & $\begin{array}{l}\text { Salgueiro, Cabrobó, Belém de São Francisco, } \\
\text { Carnaubeira da Penha }\end{array}$ & 33,4 \\
\hline \multirow{4}{*}{ Brígida } & 206 & 16672 & $\begin{array}{c}\text { Ouricuri, Parnamirim, Santa Rita da Boa Vista, } \\
\text { Orocó, Granito, Bodocó }\end{array}$ & 125,0 \\
\hline & 51 & 7365 & $\begin{array}{c}\text { Exu, Moreilândia, Granito, Serrita, Bodocó, } \\
\text { Parnamirim }\end{array}$ & 55,2 \\
\hline & 174 & 3796 & Ouricuri, Santa Cruz, Parnamirim & 28,5 \\
\hline & 158 & 2590 & Bodocó, Ouricuri & 19,4 \\
\hline Capibaribe & 16 & 9124 & $\begin{array}{c}\text { Sanharó, Belo Jardim, Jataúba, Brejo da Madre de } \\
\text { Deus, Santa Cruz do Capibaribe, Taquaritinga do } \\
\text { Norte, Toritama, Vertentes, Frei Miguelinho, } \\
\text { Riacho das Almas, Caruaru, Cumaru, Surubim, } \\
\text { Passira, Salgadinho, Limoeiro }\end{array}$ & 68,4 \\
\hline \multirow{2}{*}{ Moxotó } & 55 & 6606 & Ibimirim, Inajá & 49,5 \\
\hline & 171 & 4222 & Custódia, Sertânia, Ibimirim & 31,7 \\
\hline \multirow{3}{*}{ Garças } & 204 & 4724 & Lagoa Grande, Santa Maria do Boa Vista & 35,4 \\
\hline & 40 & 3272 & $\begin{array}{c}\text { Santa Filomena, Santa Cruz, Dormentes, Lagoa } \\
\text { Grande }\end{array}$ & 24,5 \\
\hline & 44 & 3247 & Santa Filomena, Santa Cruz & 24,4 \\
\hline
\end{tabular}

Em sequência à estimativa dos volumes armazenáveis foi realizado o estudo do risco de salinização. Com o cruzamento dos dados obtidos - solos aluvionares selecionados, solos salinos,

Silva Filho, E. L.; Caetano, T. O.; Ferreira, T. S. G.; Cirilo, J. A., Vasconcelos, R. S.; Albuquerque, T. B. V. 
bacias de drenagem e cursos d'água, foi possível observar todo o percurso do escoamento superficial até chegar na aluvião estudada.

A Tabela 3 apresenta o resultado da classificação quanto ao risco de salinização por tipo de solo. O Vertissolo Háplico apresenta a maior e Neossolo Qartzarênico a menor capacidade de salinização.

Tabela 3. Ordenamento dos solos quanto à capacidade das propriedades salinas

\begin{tabular}{ll}
\hline Colocação & Tipo de Solo \\
\hline 1 & Vertissolo Háplico \\
2 & Planossolo Háplico \\
3 & Cambissolo Háplico
\end{tabular}
4
5
Luvissolo Crômico
Neossolo Quartzarênico

Fonte: Autores, 2019.

$\mathrm{Na}$ Figura 5 estão dispostos a espacialização dos solos selecionados em todo o estado de Pernambuco. Pode-se verificar que algumas Unidades de Planejamento possuem em sua área uma maior cobertura de solos com propriedades salinas, como é o caso das bacias dos rios Pajeú, Moxotó e Terra Nova. A região metropolitana do Recife e a Zona da Mata são as regiões com as menores presenças de solos salinos. A região do Agreste também apresenta diversas áreas com identificação de solos propensos à salinização.

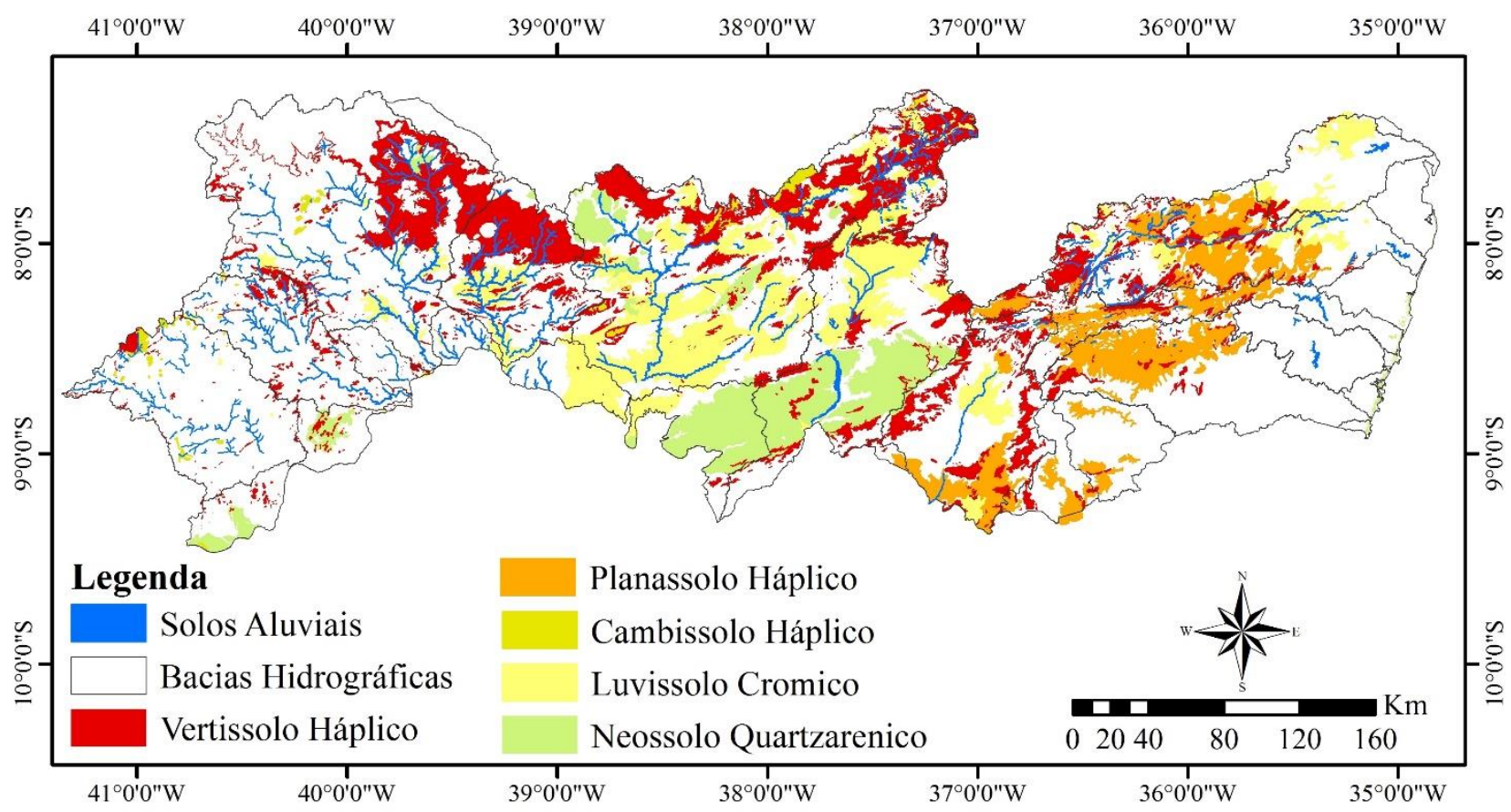

Figura 5. Espacialização dos solos susceptíveis à salinização e dos solos aluviais por unidade de planejamento.

As aluviões selecionadas foram analisadas a partir de toda a área contribuinte, a fim de observar quais os solos por onde esse escoamento se processaram. O recorte foi feito por unidade de planejamento onde se encontram as aluviões selecionadas.

A aluvião do rio Capibaribe (Figura 6) apresenta solos com menor risco de salinização próximo à nascente (Poção, Sanharó, Belo Jardim e Jataúba), havendo maior incidência de Vertissolo Háplico e de solos não salinos. Ao aproximar-se de Santa Cruz do Capibaribe há presença de solos tipo Planossolo Háplico e algumas manchas de Luvissolo Crômico. De Vertentes a Surubim a predominância é de Planossolos Háplicos, com a existência de Vertissolos Háplicos, nas áreas mais próximas à aluvião, e de manchas de Luvissolos Crômicos. No Médio Capibaribe, região próxima a Limoeiro, prevalecem solos do tipo Luvissolo Crômico.

Gusmão (2016) relatou, em pesquisas realizadas entre 2013 e 2015 em poços na aluvião na região do Alto Capibaribe, altos índices de condutividade elétrica, relacionados à salinidade, sendo ainda verificada uma sensível diminuição desses valores após a ocorrência de chuvas e consequente aumento dos níveis de água na aluvião. Foram registrados para um mesmo 
conjunto de poços valores de condutividade elétricas na estação seca variando entre 3,38 a 23,2 $\mathrm{mS} / \mathrm{cm}$ e após as chuvas valores entre 0,641 e 4,12 $\mathrm{mS} / \mathrm{cm}$. Também para o Alto Capibaribe, em pesquisas realizadas em poços na aluvião do trecho do rio que divide Santa Cruz do Capibaribe e Brejo da Madre de Deus, Silva (2018) encontrou comportamento da variação da condutividade elétrica que vão ao encontro dos publicados por Gusmão (2016).

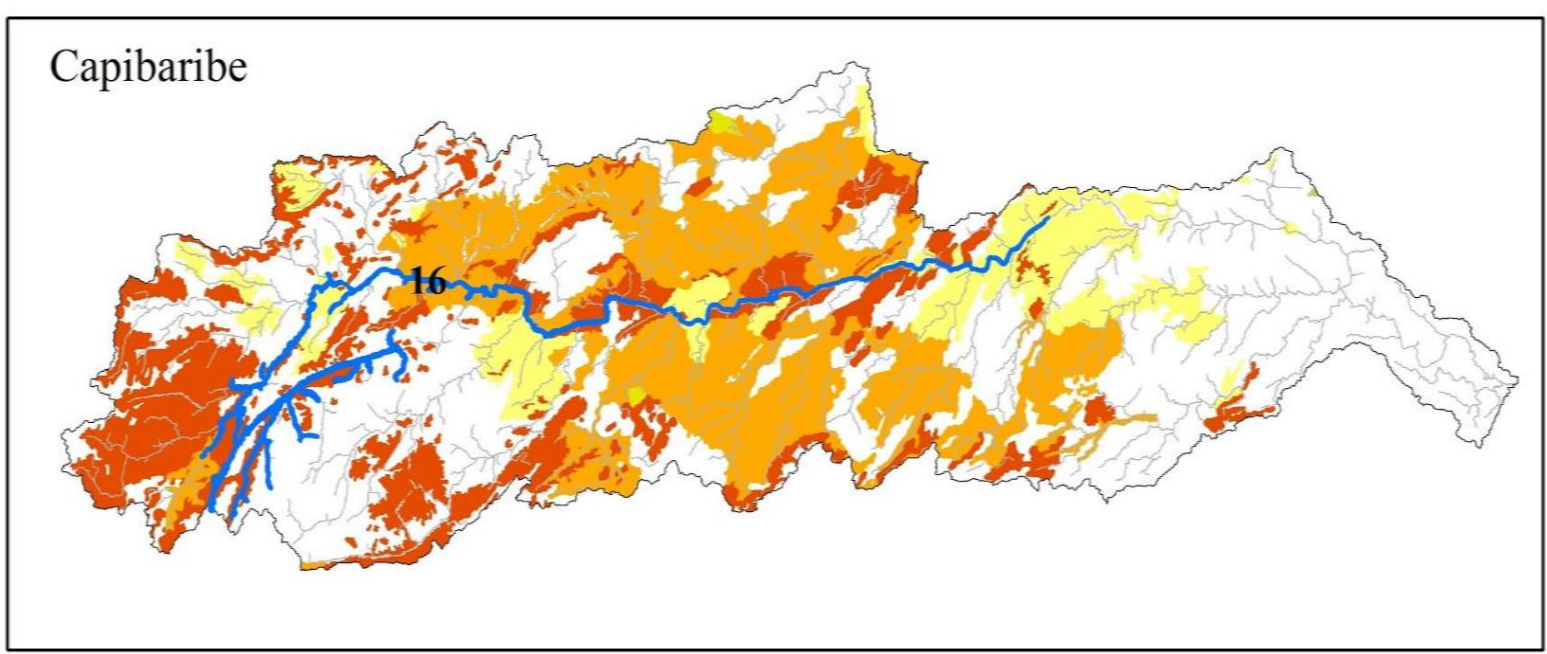

\section{Legenda}

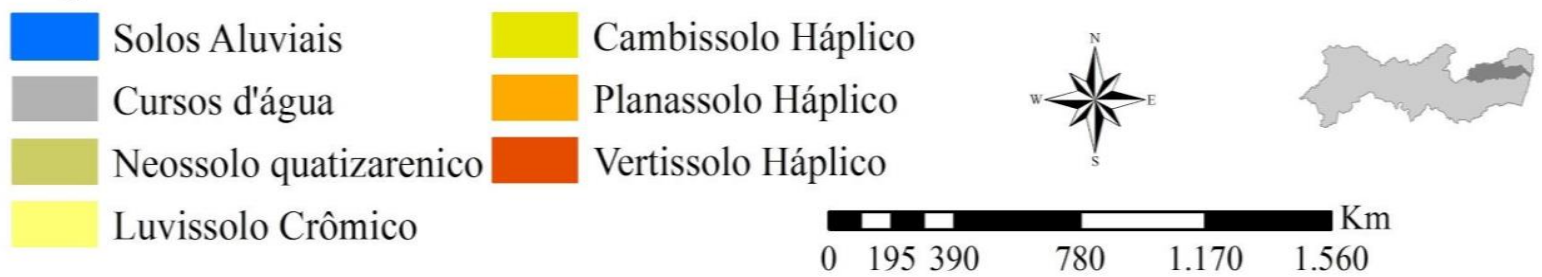

Figura 6. Espacialização dos solos susceptíveis a salinização e dos solos aluviais para bacia do rio Capibaribe.

Na bacia do rio Moxotó estão inseridas duas grandes aluviões, identificadas pelas numerações 171 e 55 (Figura 7). A aluvião ID 171, trecho mais a montante da bacia (municípios de Custódia e Sertânia), tem contato direto com o solo do tipo Luvissolo Crômico em quase toda a sua extensão e pequenas áreas de contato com o Vertissolo Háplico. Na bacia de contribuição há grandes áreas de solos não salinos, mais distante da mancha aluvionar. Análises feitas nas águas das aluviões nesta região do alto vale do rio Moxotó, Leal et al. (2000) relataram que a salinidade tende a ter diminuição de montante para jusante, no sentido em que aumenta a capacidade de armazenamento da aluvião.

A aluvião ID 55 possui a margem direita quase que totalmente em contato com Neossolos Quartzarênicos e a margem esquerda parte em contato com Neossolos Quartzarênicos, bem como parte em contato com solos não salinos.

Na bacia do rio Pajeú a composição dos solos varia bastante a depender da área (Figura 8), tendo de maneira generalizada, solos com maior potencial salino ao norte do que ao sul da bacia. $\mathrm{Na}$ área da aluvião 128 , região mais próxima à Paraíba, há majoritária presença de Vertissolos Háplicos, mais salinos. Um pouco mais a jusante da bacia, área da aluvião 151, a existência de solos com alta propriedade salina melhora um pouco em relação à anterior, mas ainda é majoritariamente influenciada por Vertissolos Háplicos. Nas regiões que drenam para a aluvião 133, maior mancha aluvionar do estado, também há variações a depender do trecho. $\mathrm{Na}$ porção que fica predominantemente no município de São José do Belmonte ocorrem próximos à aluvião solos não salinos e Neossolos Quartzarênicos e há uma grande mancha de Vertissolo Háplico mais ao norte. Na fração da aluvião que está englobada em sua maior parte no município de Mirandiba, há contato com Luvissolos Crômicos, Neossolos Quartzarênicos, presença de solos não salinos e Vertissolo Háplico na área drenada. No município de Serra Talhada, maior extensão da aluvião, há forte presença de solos salinos ao norte (Vertissolos Háplicos e Luvissolos Crômicos em maior parte e 
Cambissolos Háplicos em menor parte), solos não salinos são observados na porção média e
Luvissolos Crômicos na porção sul, bem como nos municípios de Floresta e Belém de São Francisco.

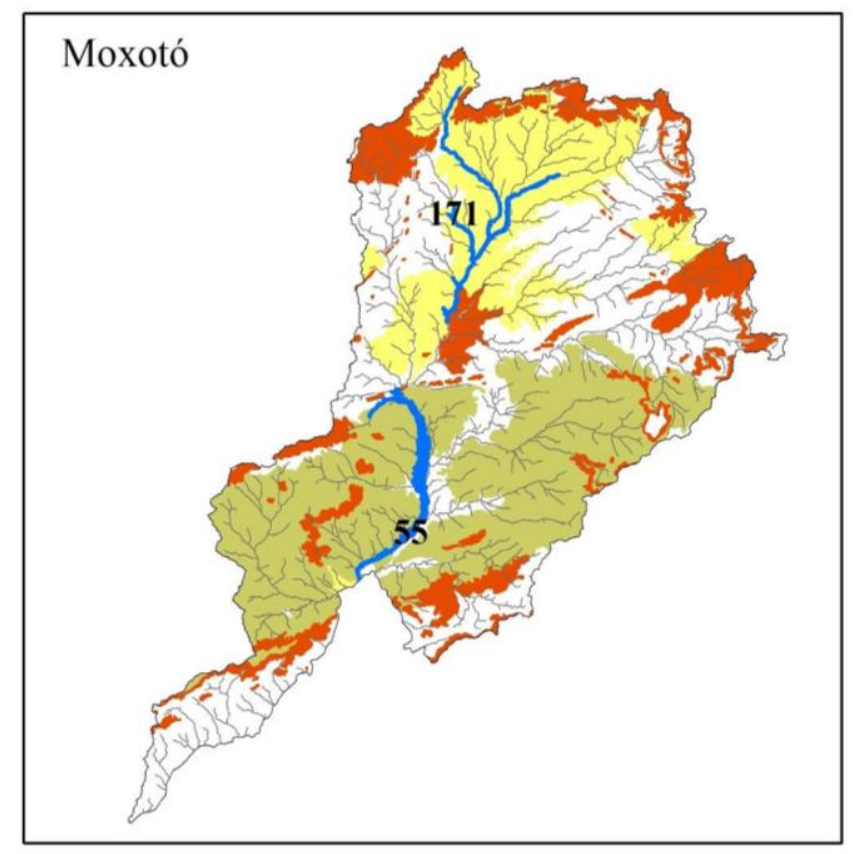

\section{Legenda}

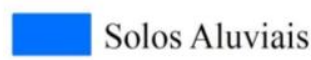

Cursos d'água

Neossolo quatizarenico

Luvissolo Crômico

Cambissolo Háplico

Planassolo Háplico

Vertissolo Háplico

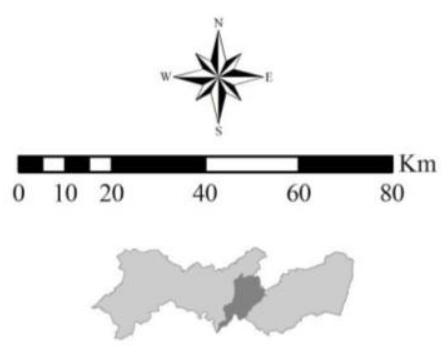

Figura 7. Espacialização dos solos susceptíveis a salinização e dos solos aluviais para bacia do rio Moxotó.

Análises realizada por Cantalice et al., (2016) em uma barragem subterrânea na bacia do Rio Jacu, localizado na região superior de Pajeú, observaram que durante a construção da barragem no período seco os sais foram concentrados na água de irrigação, no período chuvoso subsequente a condutividade elétrica diminuiu, sendo classificada como baixa salinidade $(0,95 \mathrm{dS} / \mathrm{m})$.

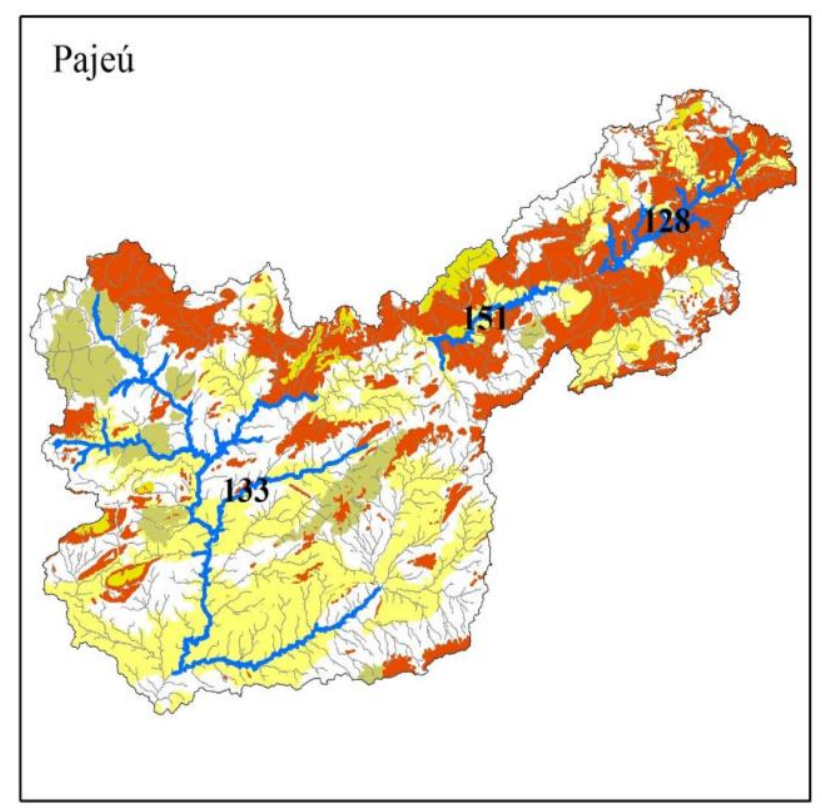

\section{Legenda}

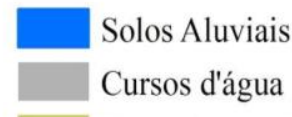

Neossolo quatizarenico Luvissolo Crômico

Cambissolo Háplico

Planassolo Háplico

Vertissolo Háplico

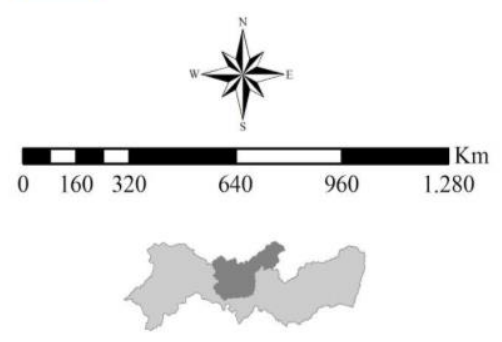

Figura 8. Espacialização dos solos susceptíveis à salinização e dos solos aluviais para a bacia do rio Pajeú.

Vale ressaltar que na região desta bacia encontra-se o Núcleo de Desertificação de Cabrobó, que abrange os municípios de Belém do São Francisco, Cabrobó e Floresta (CGEE, 2015;
Farias e Vieira, 2019). São áreas com extremos processos de degradação. Entre as diferentes causas que aceleram o processo de desertificação encontra-se a salinização dos solos, a qual é

Silva Filho, E. L.; Caetano, T. O.; Ferreira, T. S. G.; Cirilo, J. A., Vasconcelos, R. S.; Albuquerque, T. B. V. 
resultante do acúmulo de sais solúveis nas camadas agricultáveis do solo, onde o manejo agrícola inadequado é um dos principais responsáveis (Castro e Santos, 2020). Tal processo pode ocorrer através da ação humana, através de ações antrópicas ou por características ambientais (Daliakopoulos et al., 2016), no entanto áreas com solos com propriedades salinas deve-se ter um maior cuidado para qual seu uso é destinado e no manejo aplicado.

As práticas agrícolas impróprias para as características do solo dessa região têm causado redução da produtividade, perda da fertilidade e salinização do solo (Silva e Silva, 2015).

$\mathrm{Na}$ bacia do rio Terra Nova foram avaliadas duas aluviões, cuja identificação é 210 e
211 (Figura 9). O bolsão aluvionar da ID 210, em suas cabeceiras, tem quase toda a sua área cercada por solos do tipo Vertissolo Háplico (Serrita, Verdejante, norte de Salgueiro e norte de Terra Nova) e Luvissolo Crômico nas áreas mais a jusante (sul de Terra Nova, sul de Salgueiro e Cabrobó), desta forma apresentando alto potencial de salinização. No caso da aluvião ID 211, a maior parte de sua área não está inserida diretamente em solo salino. Entretanto, na sua bacia de contribuição existem algumas porções com solo do tipo Vertissolo Háplico e seu exutório encontra-se no Luvissolo Crômico, área onde tende a apresentar risco médio de salinização.

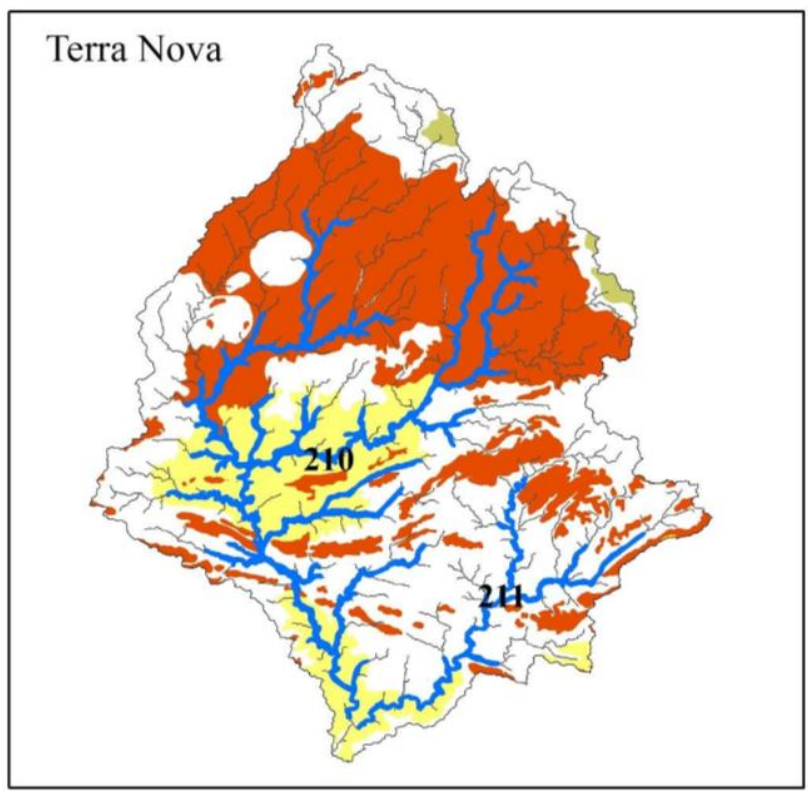

\section{Legenda}

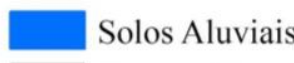

Cursos d'água

Neossolo quatizarenico Luvissolo Crômico Cambissolo Háplico Planassolo Háplico Vertissolo Háplico

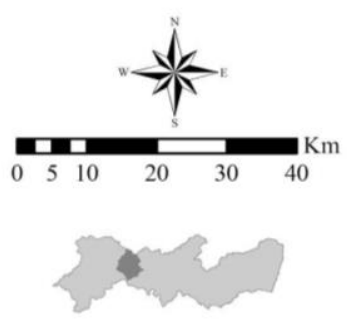

Figura 9. Espacialização dos solos susceptíveis à salinização e dos solos aluviais para a bacia do rio Terra Nova.

Na bacia do rio Brígida a maior parte da área é de solos não salinos, embora haja presença considerável de solos salinos (principalmente Vertissolos Háplicos) na parte nordeste da bacia (Figura 10). Na área da nascente do rio Brígida há um domínio de Vertissolos Háplicos, que estão em contato com a aluvião ID 51 em toda sua extensão, havendo alto risco de salinização deste segmento da aluvião. Na área da aluvião ID 206, que é bastante extensa, há contato com Vertissolos Háplicos mais a montante, prevalecendo solos não salinos (o que ocorre na maior parte de área de contribuição) à medida que vai se adentrando o município de Parnamirim. Há uma pequena presença de Luvíssolos Crômicos em volta da aluvião na região de divisa entre Parnamirim e
Santa Maria da Boa Vista. A aluvião ID158, que engloba praticamente o município de Bodocó, tem a imensa maioria de sua área de contribuição composta por solos não salinos, havendo apenas pequenas manchas de solos salinos (Cambissolos Háplicos, Vertissolos Háplicos e Luvissolos Crômicos). Na área da aluvião ID 174 a quase totalidade é de solos não salinos, havendo um pequeno trecho em contato com uma mancha não muito larga de Luvissolos Crômicos.

Análises realizadas nas águas de uma barragem subterrânea no oeste da bacia do Brígida (Oliveira et al., 2007) apontaram para uma alta salinidade (condutividade elétrica de $0,079 \mathrm{dS} / \mathrm{cm}$ ) e baixa sodicidade (RAS 2,69). 


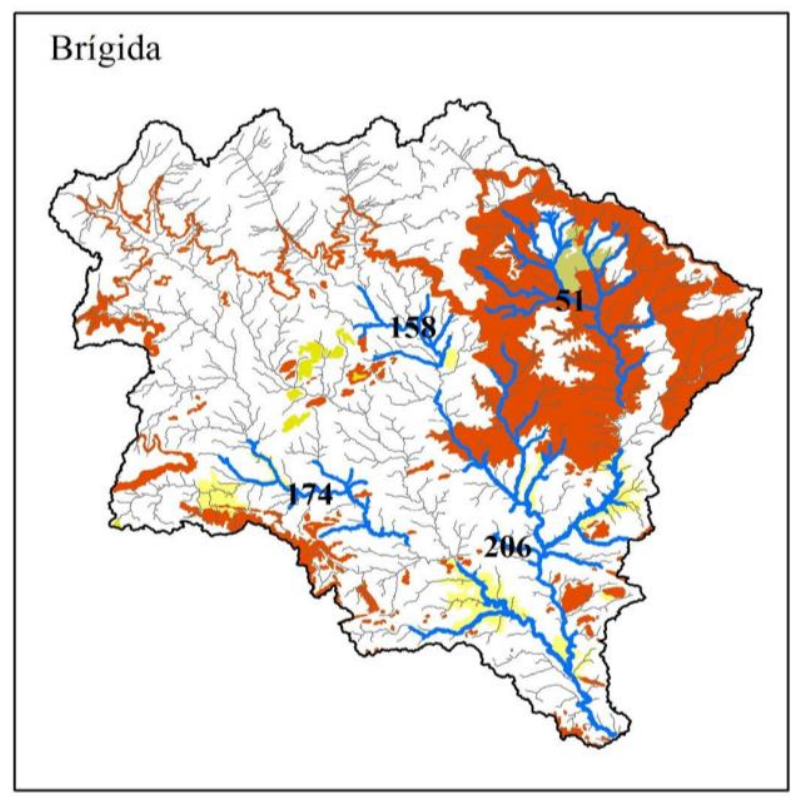

\section{Legenda}

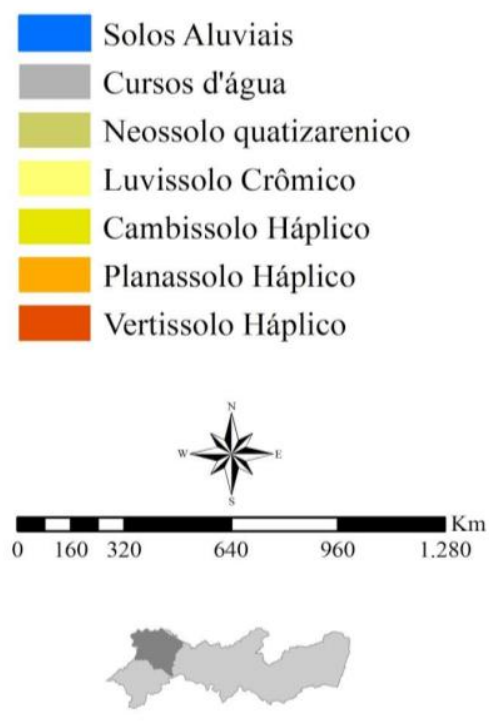

Figura 10. Espacialização dos solos susceptíveis a salinização e dos solos aluviais para bacia do rio Brígida.

$\mathrm{Na}$ bacia do rio das Garças como um todo prevalecem solos não salinos (Figura 11). A aluvião ID 204, em nenhum segmento do seu comprimento tem interface com algum solo tido como salino. Na sua bacia de contribuição há segmentos de Vertissolo Háplico, entretanto esses solos são esparsos e pontuais, não apresentando risco iminente à salinização. Para a aluvião ID 40 o quadro se repete. A aluvião ID 44 possui no seu trecho mais a montante, região da divisa entre Santa Filomena e Santa Cruz, uma significativa presença de Vertissolos Háplicos, contribuindo para a existência do risco de salinização

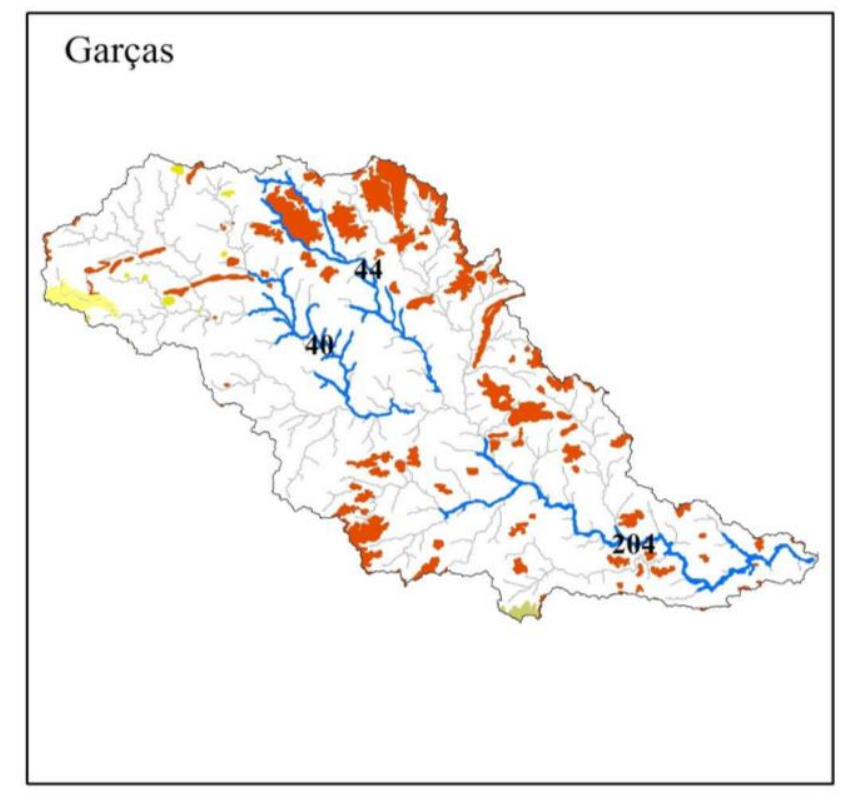

\section{Legenda}

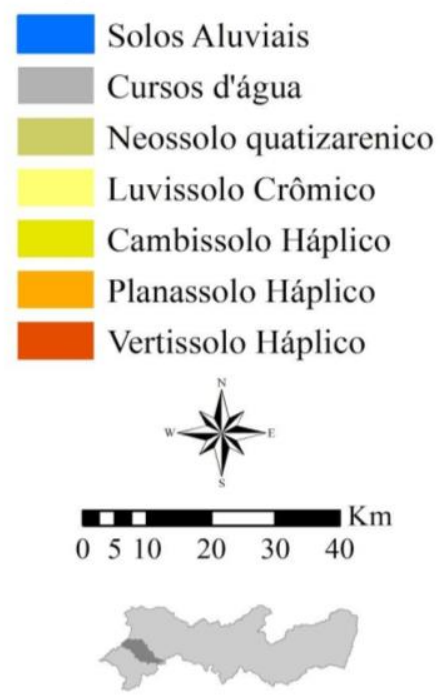

Figura 11. Espacialização dos solos susceptíveis a salinização e dos solos aluviais para bacia do rio das Garças.

\section{Conclusões}

1. O Estado de Pernambuco apresenta consideráveis áreas de solos aluviais com significativa capacidade de armazenamento e potencial para utilização de água, seja por explotação direta ou mais ainda a partir da construção de barragens subterrâneas.

Silva Filho, E. L.; Caetano, T. O.; Ferreira, T. S. G.; Cirilo, J. A., Vasconcelos, R. S.; Albuquerque, T. B. V. 
2. As manchas de aluvião estão bem distribuídas por todas as regiões do estado, tendo destacada presença na área do semiárido, o que reforça a importância de avaliação dos segmentos de aluvião a explorar.

3. O risco de salinização é bem presente. A maior parte das 15 maiores aluviões do estado apresentaram em pelo menos algum trecho risco de médio a muito alto para a ocorrência de salinização. Apesar disso, a análise apresentada mostra que muitos segmentos das aluviões têm baixo risco, podendo ser aproveitadas para captação direta da água ou armazenamento por construção de barragens subterrâneas.

4. As informações espaciais das características das aluviões e dos locais onde o risco de salinização é maior são essenciais para avaliação de alocação de barragens subterrâneas. Recomenda-se também considerar a necessidade de manejo adequado das estruturas de armazenamento e captação, de forma a minimizar os efeitos da evapotranspiração e do acúmulo de sais na água represada.

\section{Agradecimentos}

Os autores agradecem à Fundação de Amparo à Ciência e Tecnologia de Pernambuco (FACEPE) pelo apoio no desenvolvimento da pesquisa, por meio de bolsas de Pós-Graduação e de Iniciação Científica, bem como ao $\mathrm{CNPq}$, também pela concessão de bolsas e ao projeto Capes $\quad n^{\circ} 88887.163498 / 2018-00 \quad$ pelo financiamento e bolsa de pós-doutorado.

\section{Referências}

Adhamum, A., Riksenuma, M., Ouessar, M., Coen, R., 2016. Identification of suitable sites for rainwater harvesting structures in arid and semi-arid: A review. International Soil and Water Conservation Research 4, 108-120. DOI:https://doi.org/10.1016/j.iswcr.2016.03.0 01.

Agarwal, R., Garg, P.K., 2016. Remote Sensing and GIS Based Groundwater Potential \& Recharge Zones Mapping Using Multi-Criteria Decision Making Technique. Water Resour Manage 30, $243 \quad-260 . \quad$ DOI: https://doi.org/10.1007/s11269-015-1159-8.

AGEITEC - EMBRAPA. Cambissolos háplicos. Rio de Janeiro, 2014a. Disponível: http://www.agencia.cnptia.embrapa.br/gestor/s olos_tropicais/arvore/cont000gn1sf65m02wx5 ok0liq1mqzx3jrec.html. Acesso: 3 dez. 2018.

AGEITEC - EMBRAPA. Luvissolos crômicos. Rio de Janeiro, 2014b. Disponível: http://www.agencia.cnptia.embrapa.br/gestor/s olos_tropicais/arvore/cont000gn230xhm02 wx 5ok0liq1mqv181o7y.html. Acesso: 3 dez. 2018.

AGEITEC - EMBRAPA. Neossolo quartzarênicos. Rio de Janeiro, 2014c. Disponível:

http://www.agencia.cnptia.embrapa.br/gestor/s olos_tropicais/arvore/cont000gn230xho02wx5 ok0liq1mqtarta66.html. Acesso: 3 dez. 2018.

AGEITEC - EMBRAPA. Planossolos háplicos. Rio de Janeiro, 2014d. Disponível: http://www.agencia.cnptia.embrapa.br/gestor/s olos_tropicais/arvore/cont000gn362j9y02wx5 ok0liq1mq86zqh78.html. Acesso: 3 dez. 2018.

AGEITEC - EMBRAPA. Vertissolos háplicos. Rio de Janeiro, 2014e. Disponível: http://www.agencia.cnptia.embrapa.br/gestor/s olos_tropicais/arvore/cont000gn362ja002wx5 ok0liq1mqeukhsfe.html. Acesso: 3 dez. 2018.

Alves, E. J. C., Rêgo, J. C., Galvão, C. de O., Vieira, J. B. de A. 2018. Limits and conditions for the exploitation of alluvial aquifers in the Brazilian semi-arid region. Revista Brasileira de Recursos Hídricos, 23, 1-8. DOI: https://doi.org/10.1590/2318 0331.0318160049

Araújo, D.C. dos S., Montenegro, S.M.G.L., Montenegro, A. A. de A., Silva Junior, V. de P., Santos, S. M. dos., 2018. Spatial variability of soil attributes in an experimental basin in the semi-arid region of Pernambuco, Brazil. Revista Brasileira de Engenharia Agrícola e Ambiental 22, 38-44. DOI: http://dx.doi.org/10.1590/18071929/agriambi.v22n1p38-44.

Cabral, S.L., Campos, J.N.B., Silveira, C. da S., Pereira, J.M.R., 2016. O Intervalo de Tempo para uma Máxima Previsibilidade da Precipitação sobre o Semiárido Brasileiro. Revista Brasileira de Meteorologia 31, 105113. DOI: https://doi.org/10.1590/0102778631220130034.

Caetano, T.O., 2018. Disponibilidade hídrica das aluviões e as características de uso e demanda de água em comunidades rurais do semiárido pernambucano. 86f. Dissertação (Mestrado). Programa de Pós-Graduação em Engenharia Civil e Ambiental - Campus Acadêmico do Agreste, Universidade Federal de Pernambuco, Caruaru. 
Cantalice, J.R.B., Piscoya, V.C., Singh, V.P., Silva, Y.J.A.B. da, Barros, M. de F.C., Guerra, S.M.S., Filho, M.C., 2016. Hydrology and water quality of a underground dam in a semiarid watershed. African Journal of Agricultural Research 11, 2508-2518. DOI: https://doi.org/10.5897/AJAR2016.11163.

Castro, C.F., Santos, M. dos, 2020. Salinidade do Solo e Risco de Desertificação na Região Semiárida. Mercator 19, 1-13, DOI: https://doi.org/10.4215/rm2020.e19002.

Chezgi, J., Pourghasemi, H.R., Naghibi, S.A., Moradi, H.R., Zarkesh, M.K., 2016. Assessment of a spatial multi-criteria evaluation to site selection underground dams in the Alborz Province, Iran. Geocarto International 31, 628-646. DOI: http://dx.doi.org/10.1080/10106049.2015.107 3366.

Cirilo, J.A., Alves, F.H.B., Silva, L.A.C., Campos, J.H.A.L., 2014. Suporte de Informações Georreferenciadas de Alta Resolução para Implantação de Infraestrutura e Planejamento Territorial. Revista Brasileira de Geografia Física 7, 755-763. DOI: https://doi.org/10.26848/rbgf.v7.4.p755-763.

Cirilo, J.A., Alves, F.H.B., Ribeiro Neto, A., 2016. Utilização de mapeamento digital do terreno para prevenção de desastres e planejamento do uso do solo. In: Conferência Internacional do INCT para Mudanças Climáticas, São Paulo, SP.

Daliakopoulos, I.N., Tsanis, I.K., Koutroulis, A., Kourgialas, N.N., Varouchakis, A.E., Karatzas, G.P., Ritsema, C.J., 2016. The threat of soil salinity: a European scale review. Science of The Total Environment 573, 727-739. DOI: https://doi.org/10.1016/j.scitotenv.2016.08.17 7.

Dortaj, A., Maghsoudy, S., Ardejani, F. D., Eskandari, Z., 2020 A hybrid multi-criteria decision making method for site selection of subsurface dams in semi-arid region of Iran. Groundwater for Sustainable Development, 10, DOI: https://doi.org/10.1016/j.gsd.2019.100284

Eakin, H.C., Lemos, M.C., Nelson, D.R., 2014. Differentiating capacities as a means to sustainable climate change adaptation. Global Environmental Change, 27, 1-8. DOI: https://doi.org/10.1016/j.gloenvcha.2014.04.0 13.

EMBRAPA. Empresa Brasileira de Pesquisa Agropecuária. ZAPE: Zoneamento Agroecológico de Pernambuco. Disponível em:

<http://www.uep.cnps.embrapa.br/zape/>. Recife, 2001.

Farias, P.L.C. de, Vieira, B.H.R., 2019. Atuação do estado de Pernambuco no combate aos efeitos da desertificação. Revista Brasileira de Geografia Física 12, 562-573. DOI: https://doi.org/10.26848/rbgf.v12.2.p562-573.

Freire, M.B.G.S., Miranda, M.F.A., Oliveira, E.E.M., Silva, L.E. da, Pessoa, L.G.M., Almeida, B.G. de., 2014. Agrupamento de solos quanto à salinidade no Perímetro Irrigado de Custódia em função do tempo. Revista Brasileira de Engenharia Agrícola e Ambiental 18, S86-S91. DOI: https://doi.org/10.1590/1807-

1929/agriambi.v18nsupps86-s91.

Fontes Júnior, R.V. de P., Montenegro, A.A.A., Montenegro, S.M.G.L., Santos, T.E.M. dos, 2012. Estabilidade temporal da potenciometria e da salinidade em vale aluvial no semiárido de Pernambuco. Revista Brasileira de Engenharia Agrícola e Ambiental 16, 1188-1197, DOI: https://doi.org/10.1590/S141543662012001100007.

Gomes, U.A.F., Heller, L., 2016. Acesso à água proporcionado pelo Programa de Formação e Mobilização Social para Convivência com o Semiárido: Um Milhão de Cisternas Rurais: combate à seca ou ruptura da vulnerabilidade? Engenharia Sanitária Ambiental 21, 623-633. DOI: $\quad$ https://doi.org/10.1590/S141341522016128417.

Gusmão, P.T.R., 2016. Qualidade das águas captadas nas areias de aluvião. In: BRAGA, R. A. P. (Org.). Águas de Areias. Recife: Clã, 89105.

Jamali, A.A., Randhir, T.O., Nosrati, J., 2018. Site Suitability Analysis for Subsurface Dams Using Boolean and Fuzzy Logic in Arid Watersheds. Journal of Water Resources Planning and Management 144, 1-9. DOI: https://doi.org/10.1061/(ASCE)WR.19435452.0000947.

Kharazia, P., Yazdania, M. R., Khazealpour, P., 2019. Suitable identification of underground dam locations, using decision-making methods in a semi-arid region of Iranian Semnan Plain. Groundwater for Sustainable Development 9, 100240 .

DOI: https://doi.org/10.1016/j.gsd.2019.100240.

Lalehzari, R., Tabatabaei, S. H., 2015. Simulating the impact of subsurface dam construction on the change of nitrate distribution. Environmental Earth Sciences 74, 3241-3249. 
DOI: https://doi.org/10.1007/s12665-0154362-2.

Leal, O., 2000. Avaliação hidrogeológica preliminar das aluviões do alto vale do rio Moxotó-PE/Onofre Leal, José Ubaldo de Sá, João de Castro Mascarenhas. Recife: CPRM. $107 \mathrm{p}$.

Lima, A. de O., Lima-Filho, F.P., Dias, N. da S., Reis Júnior, J.A. dos, Sousa A. de M., 2018. GPR 3D Profile Of The Adequateness Of Underground Dams In A Sub-Watershed Of The Brazilian Semiarid. Rev. Caatinga 31, 523-531. DOI: https://doi.org/10.1590/198321252018v31n230rc.

Li, P., Qian, H., Wu J., 2018. Conjunctive use of groundwater and surface water to reduce soil salinization in the Yinchuan Plain, North-West China, International. Journal of Water Resources Development 34, 337-353. DOI: https://doi.org/10.1080/07900627.2018.14430 59.

Montenegro, S.M.G.L., 2012. Evaporação medida pelo método do domo em barragem subterrânea no semiárido pernambucano. XVII Congresso Brasileiro de Águas Subterrâneas e XVIII Encontro Nacional de Perfuradores de Poços, Bonito.

Oliveira, A.K.C., Silva, M. S.L., Mendonça, C.E.S., Ferreira G.B., Chaves, V.C., Silva, D.J., 2007. Avaliação qualitativa da água de barragens subterrâneas no semiárido nordestino brasileiro. Revista Brasileira de Agroecologia [Online] 2, 402-1404. Disponível: http://revistas.abaagroecologia.org.br/index.php/rbagroecologia/ article/view/7092. Acesso: 5 jun. 2020.

Ouerdachi, L., Boutaghane, H., Hafsi, R., Tayeb, T. B., Bouzahar, F., 2012. Modeling of Underground Dams Application to Planning in the Semi-Arid Areas (Biskra, Algeria). Energy Procedia 18, 426-437. DOI: https://doi.org/10.1016/j.egypro.2012.05.054

PERNAMBUCO. Secretaria de Ciência, Tecnologia e Meio Ambiente, 2006. Bacias Hidrográficas de Pernambuco. Comunigraf, Recife.

Rodrigues, F. B., 2012. Caracterização Hidrogeológica de depósito aluvial do Riacho Boa Vista no Sítio Caiçara, Afogados da Ingazeira, PE. Dissertação (Mestrado). Programa de Pós-Graduação em Geociências Centro de Tecnologia e Geociências, Universidade Federal de Pernambuco, Recife.

Santos, I. de O., Mariano, G., 2017. Sistema de informação geográfica e caracterização fisiográfica automática da bacia hidrográfica do rio Tatuoca. Revista Brasileira de Geografia Física 10, 66-879. DOI: https://doi.org/10.5935/1984-2295.20170056.

Sheikhipour, B., Javadi, S., Banihabib, M.E., 2018. A hybrid multiple criteria decisionmaking model for the sustainable management of aquifers. Environmental Earth Sciences 77, 712. DOI: https://doi.org/10.1007/s12665-0187894-4.

Silva, R.O.B. da, Montenegro, S.M.G.L., Souza, W.M. de., 2017. Tendências de mudanças climáticas na precipitação pluviométrica nas bacias hidrográficas do estado de Pernambuco. Engenharia Sanitária Ambiental 22, 579-589. DOI: $\quad$ https://doi.org/10.1590/s141341522017142481.

Silva, S.M.P. da., 1994. Sistema de Informações para Gestão e Monitoramento dos Recursos Naturais da Microrregião do Pajeú-PE. Projeto Alto Pajeú; Água no Sertão do Pajeú - O Município de Afogados da Ingazeira. Série Recursos Hídricos, 3. Recife: CPRM. 25p.

Silva, A.K. de O., Silva, H.P. de B., 2015. O processo de desertificação e seus impactos sobre os recursos naturais e sociais no município de Cabrobó - Pernambuco - Brasil. Revista Eletrônica de Humanidades do Curso de Ciências Sociais da UNIFAP [Online] 8, 203-215. Disponível: https://periodicos.unifap.br/index.php/pracs/ar ticle/view/1315. Acesso: 5 jun. 2020.

Silva, D. J., 2018. Caracterização hidrodinâmica do solo e qualidade da água da aluvião em um trecho intermitente do rio Capibaribe semiárido pernambucano. Dissertação (Mestrado). Programa de Pós-Graduação em Engenharia Civil e Ambiental - Campus Acadêmico do Agreste, Universidade Federal de Pernambuco, Caruaru.

Soares, D.B., Nóbrega, R.S., Mota Filho, F. de O., Passos, C.R.F., Borges Filho, E.F. de A., 2016. Degradação dos solos por sais em Pernambuco, Brasil. Revista Brasileira de Geografia Física 9, 1621-1628. DOI:https://doi.org/10.26848/rbgf.v9.5.p1621 $-1628$.

Stevanović, Z., 2016. Damming underground flow to enhance recharge of karst aquifers in the arid and semi-arid worlds. Environ Earth Sci 75, 114. DOI: https://doi.org/10.1007/s12665-0155086-Z. 